\title{
EFFECTS OF MEDICAL THERAPY, ALCOHOL, SMOKING, AND ENDOCRINE DISRUPTORS ON MALE INFERTILITY
}

\author{
Fábio Firmbach Pasqualotto, Antônio Marmo Lucon, Bernardo Passos Sobreiro, \\ Eleonora Bedin Pasqualotto and Sami Arap
}

PASQUALOTTO FF et al. Effects of medical therapy, alcohol, smoking, and endocrine disruptors on male infertility. Rev. Hosp. Clín. Fac. Med. S. Paulo 59(6):375-382, 2004.

Infertility affects up to $15 \%$ of the sexually active population, and in $50 \%$ of cases, a male factor is involved, either as a primary problem or in combination with a problem in the female partner. Because many commonly encountered drugs and medications can have a detrimental effect on male fertility, the medical evaluation should include a discussion regarding the use of recreational and illicit drugs, medications, and other substances that may impair fertility. With the knowledge of which drugs and medications may be detrimental to fertility, it may be possible to modify medication regimens or convince a patient to modify habits to decrease adverse effects on fertility and improve the chances of achieving a successful pregnancy.

Concern is growing that male sexual development and reproduction have changed for the worse over the past 30 to 50 years. Although some reports find no changes, others suggest that sperm counts appear to be decreasing and that the incidence of developmental abnormalities such as hypospadias and cryptorchidism appears to be increasing, as is the incidence of testicular cancer. These concerns center around the possibility that our environment is contaminated with chemicals - both natural and synthetic - that can interact with the endocrine system.

KEYWORDS: Semen. Endocrine. Sperm. Alcohol. Cigarettes. Drugs.

Lately, there has been increasing concern about the potential of substances in the environment to disrupt endocrine systems in humans and wildlife. ${ }^{1-4}$ The primary emphasis to date has been on substances that might mimic estrogen and could interfere with the normal functioning of the endocrine system. The list of chemicals that are known to affect reproduction in humans via endocrine mechanisms include pesticides (DDT and its metabolites), polychlorinated biphenyls, dioxins, naturally occurring plant estrogens (phytoestrogens), and mycotoxins. ${ }^{5-8}$ Several other chemicals (e.g. alkylphenols and phthalates) have been shown to interfere with endocrine-mediated processes, but evidence for effects on reproductive functions in vivo is lacking. Current methods for assessing human and wildlife health effects are generally targeted at detecting effects rather than mechanisms and may not adequately evaluate effects on endocrine system. ${ }^{1,5,6}$ Infertility affects up to $15 \%$ of the

From the Department of Urology, Hospital das Clínicas, Faculty of Medicine, University os São PAulo - São Paulo/SP, Brazil and University of Caxias do Sul - Caxias do Sul/RS, Brazil. E-mail: fabio@conception-rs.com.br

Received for publication on February 27, 2004. Accepted for publication on April 22, 2004. sexually active population, and in $50 \%$ of cases, a male factor is involved, either as a primary problem or in combination with a problem in the female partner. ${ }^{9}$ Complete evaluation of the male includes a detailed, directed history evaluating for specific risk factors that may impair fertility, a directed physical examination, and laboratory testing. Because many commonly encountered drugs and medications can have a detrimental effect on male fertility, the medical evaluation should include a discussion regarding the use of recreational and illicit drugs, medications, and other substances used by the patient that may adversely affect 
fertility. ${ }^{5,6}$ Equipped with the knowledge of which drugs and medications may be detrimental to fertility, it may be possible to modify medication regimens or convince a patient to modify habits to decrease adverse effects on fertility and improve the chances of achieving a successful pregnancy.

Basically, there are 4 mechanisms by which drugs and medications impair male fertility: by exerting a gonadotoxic effect on the testicles, by altering the hypothalamic-pituitarygonadal (HPG) axis, by impairing ejaculation and erectile function, and by decreasing libido. ${ }^{10}$

Gonadotoxins directly affect testicular sperm production, resulting in suboptimal sperm density, maturation, motility, or morphology. ${ }^{10-13}$ Several substances alter the delicately balanced HPG axis, causing either a decline in pituitary-secreted gonadotropins or an alteration in intratesticular testosterone concentrations. ${ }^{1}$ Ejaculation may be impaired by drugs that cause retrograde ejaculation, block spinal reflexes, or inhibit emission, resulting in a dry ejaculate. Erectile dysfunction may occur with drugs that interfere with either neurologic or vascular mediated events necessary for normal erection to occur. Finally, several medications interfere with normal male libido through their actions on the central nervous system (CNS). ${ }^{1,5,6}$

\section{Recreational and illicit drugs}

Agents in this category that can affect male fertility include alcohol, tobacco, and illicit drugs.

\section{Alcohol}

Long-term effects of chronic alcohol use include erectile dysfunction, reduced libido, and gynecomastia. ${ }^{14}$ One mechanism of these effects is a reduction in serum testosterone caused by decreased testicular production and increased metabolic clearance in the liver. It is thought that alcoholism and hepatic cirrhosis cause alterations in the HPG axis, resulting in testicular dysfunction. ${ }^{14}$ In addition, the oxidation of alcohol competes with testicular production of testosterone. These mechanisms lead to subsequent decrease in semen volume and sperm density. Another factor appears to be an elevation in serum estrogen caused by peripheral conversion of testosterone to estrogen through increased activity of the enzyme aromatase, which is present both in the liver and in peripheral fat cells. ${ }^{15}$

"Social" or light alcohol ingestion does not appear to interfere with semen quality. ${ }^{6}$ However, excessive acute alcohol intake does have adverse effects on male fertility by causing decreased serum testosterone concentrations. Impairment of spinal reflexes, also caused by excessive alcohol abuse, leads to reduced sensation and innervation of the penis, and thus may also contribute to erectile dysfunction. ${ }^{14}$

\section{Cigarette smoking}

Many studies have examined the effects of cigarette smoking on fertility, and cumulative evidence suggests that smoking has a significant negative impact on sperm production, motility, and morphology. ${ }^{6}$ Several reports demonstrated that the mutagenic and carcinogenic components of cigarette smoke have adverse effects on rapidly dividing cells, including germ cells in the testis. ${ }^{16}$ However, recently we observed that no differences were seen in testicular volume, FSH and testosterone levels, or sperm concentration, motility, and morphology in a population of fertile patients who smoke or drink coffee compared to patients that do not have these habits. ${ }^{17}$

Animal studies have shown that nicotine, cigarette smoke, and/or polycyclic aromatic hydrocarbons can cause testicular atrophy, poor sperm morphology, and overall impaired spermatogenesis, leading to the presence of oligospermia ( $<20 \times 10^{6} \mathrm{sperm} /$ $\mathrm{mL}$ or $<40 \times 10^{6}$ sperm) and teratospermia ( $<4 \%$ normal sperm forms). Serum levels of prolactin and estradiol $\left(\mathrm{E}_{2}\right)$ are also elevated in smokers. This was most pronounced in smokers who had low sperm counts compared to smokers who had normal sperm counts. Estradiol impairs spermatogenesis via several different mechanisms, including alteration of the HPG axis. Studies have also show that elevated $\mathrm{E}_{2}$ levels can cause increased catecholamine levels, which in turn can produce ischemia of the seminiferous tubules. While the exact mechanism for the apparent elevation in $\mathrm{E}_{2}$ in smokers is unknown, it appears to be due to increased production of this hormone rather than to decreased metabolic clearance.

It has been reported that cigarette smoking causes increased serum levels of norepinephrine, which in turn can increase aromatization of testosterone to $\mathrm{E}_{2}$ in Sertoli cells in vitro. ${ }^{18}$ While it is unclear exactly how smoking directly affects spermatogenesis, overwhelming evidence suggests that it has an unfavorable impact on fertility. Thus, every effort should be made to counsel both partners to stop the use of tobacco as part of their infertility treatment.

\section{Illicit drugs}

Several illicit drugs are detrimental to male fertility and should be avoided, especially in men trying to establish a pregnancy. ${ }^{10}$ Marijuana interferes with spermatogenesis by decreasing sperm density and motility and decreasing the number with morphologic abnormalities. ${ }^{19}$ High doses of opiates lead to a decline in libido and erectile function. Opiates suppress the luteinizing hormone $(\mathrm{LH})$ and 
luteinizing hormone releasing factor (LH-RH), leading to a decline in testosterone production. The pituitary gland itself may also be directly suppressed by opiates. High doses of cocaine impair erectile function, and high doses of amphetamines have been shown to cause diminished libido. ${ }^{6}$

\section{Antihypertensives}

While medical treatment of hypertension is important, urologists treating male infertility must be knowledgeable about the agents that cause the most significant impairments in testicular function. ${ }^{6,10}$ While fertility remains desirable, men using these medications can often be switched to another class of antihypertensive medications while attempting pregnancy.

Most antihypertensive agents exert a deleterious effect on fertility by impairing sexual function. However it is important to keep in mind that hypertension occurs more commonly in the older population, a group known to have a higher incidence of erectile dysfunction in general. The use of antihypertensives in conjunction with vascular insufficiency may exacerbate inadequate blood flow to the male genitals. $^{19}$

Diuretics such as the thiazides decrease blood flow to the penis by reducing vascular resistance. ${ }^{6,10}$ Propranolol has been noted to cause a decrease in both libido and erectile function. ${ }^{6,10,19}$ Cardioselective agents such as atenolol and metoprolol appear to have less deleterious effects on male sexual function. Vasodilators themselves do not inhibit sexual function because they do not interfere with sympathetic reflexes. However, they are often used in conjunction with beta-blockers and diuretics that do affect potency and libido. Efforts should be made to refer patients back to their clinicians to change beta-blockers to other agents such as angiotensin converting enzyme (ACE) inhibitors.

Due to its effect on the HPG axis, spironolactone may cause profound fertility problems. This agent also prevents the binding of dihydrotestosterone (DHT) to its receptor and inhibits the production of testosterone, which may result in reduced libido, erectile dysfunction, and significantly decreased sperm production. ${ }^{6,10,19}$

\section{Calcium channel blockers}

Calcium influx is critical for the normal acrosome reaction to occur. ${ }^{20}$ Thus, calcium channel blocking $(\mathrm{CaCB})$ medications have recently received particular attention as potential inhibitors of the normal fertilization process. The calcium influx required during the acrosome reaction may be impaired directly by the effects of $\mathrm{CaCBs}$ or by insertion of the $\mathrm{CaCBs}$ into the plasma membrane of the sperm head. This insertion causes an alteration in the surface molecules expressed on the sperm head that are also required for normal fertilization to occur. $^{20,21}$

Clinical studies have shown that cessation of the $\mathrm{CaCB}$ may reverse this process and restore the fertility in some otherwise infertile men. Other reports, however, have failed to show any adverse effect of $\mathrm{CaCBs}$ on male fertility. ${ }^{22}$ While the effects of CaCBs on male fertility remains unclear, it may be prudent to discuss a switch to another antihypertensive agent with patients who are taking these medications and who desire fertility.

\section{Alpha-adrenergic blockers}

Agents such as alfuzosin, tamsulosin, terazosin, and doxazosin are commonly prescribed for the treatment of benign prostatic hyperplasia, and are also used in younger men with voiding complaints. They function by blocking the motor sympathetic adrenergic nerve supply to the prostate, resulting in a reduction in urethral pressure. ${ }^{23}$ Differences in affinity for the areceptor subtypes determine the sideeffect profile for the individual agents.

The more selective alpha-blocking agents, by reducing smooth muscle tone at the bladder neck, can cause retrograde ejaculation. ${ }^{6}$ While patients tend to better tolerate and are more compliant with alfuzosin and tamsulosin than doxazosin, terazosin, and prazosin, retrograde ejaculation is more commonly associated with tamsulosin, occurring in about $8.5 \%$ of men. While ganglion blockers (methyldopa, guanethidine, and reserpine) can have similar side effects on male sexual function, they are rarely used clinically. ${ }^{6,23}$

\section{Angiotensin converting enzyme inhibitors}

Agents such as captopril and enalapril have not been associated with male sexual dysfunction or infertility, nor have direct vasodilators effects such as hydralazine and minoxidil. ${ }^{6}$

\section{Psychotherapeutic agents}

Psychotherapeutic agents exert much of their effect on male fertility by inhibiting sexual function and libido.

\section{Antipsychotics}

Most antipsychotics block dopamine in the CNS, leading to suppression of the HPG axis and decreased libido. Some antipsychotic agents also have alpha-adrenergic blocking effects that block innervation of the internal genital organs. In addition, some are vasodilators that can redirect blood away from the penis and cause erectile dysfunction. It is important to realize, 
however, that antipsychotics can bring about important changes in overall well-being that may far outweigh any of the deleterious effects mentioned above. ${ }^{14,19}$

\section{Tricyclic antidepressants}

The use of tricyclic antidepressants or selective serotonin reuptake inhibitors (SSRIs) can lead to erectile dysfunction and reduced libido through their anticholinergic and sedative side effects. ${ }^{6,14,19}$ They have also been shown to impair ejaculation. Because these agents cause a delay in ejaculation, they have been used to treat men with premature ejaculation.

Perhaps the most significant side effect of antidepressants, however, is the potential for substantial elevation in serum prolactin concentrations. Hyperprolactinemia suppresses secretion of gonadotropin releasing hormone $(\mathrm{GnRH})$ from the hypothalamus, and the high prolactin levels inhibit LH from binding to Leydig cells in the testes. These actions lead to significant but reversible suppression of spermatogenesis. If fertility is desired, the initial treatment of hyperprolactinemia caused by antidepressant use is a change to another class of medication. However, if this is not possible, cabergoline or bromocriptine can be administered.

\section{Other psychotherapeutic agents}

Phenothiazines can cause hyperprolactinemia and negatively affect male fertility in the same way as tricyclic antidepressants; thus, treatment is similar. ${ }^{6,10,14,19}$ Monoamine oxidase inhibitors, another prominent class of antidepressants, can cause erectile dysfunction or ejaculatory problems. Finally, lithium carbonate has been shown to decrease the action of dopamine in the CNS, causing decreased libido and potency.

\section{Chemotherapeutic agents}

The use of chemotherapeutic agents is necessary in the treatment of many malignancies that occur in young men, including Hodgkin's lymphoma, testicular cancer, and acute lymphocytic leukemia. ${ }^{6,10,24-26}$ Chemotherapeutic agents have the potential to damage both germ cells and the supporting Sertoli cells, leading to severe oligospermia or azoospermia immediately following most courses of chemotherapy. While Leydig cells are less susceptible to injury than Sertoli cells, they may still demonstrate a degree of dysfunction, resulting in increased LH levels and low-normal testosterone levels. The most gonadotoxic chemotherapeutic agents include alkylating agents (cyclophosphamide, chlorambucil, and busulfan), antimetabolites (cytarabine), vinca alkaloids (vinblastine), and others (cisplatin, procarbazine, mechlorethamine). ${ }^{27-29}$

While nearly all men will have profound defects in spermatogenesis immediately following chemotherapy, the ability to regain spermatogenesis following treatment varies depending on the individual agents used, the dose of each, and the length of treatment. Clearly, total destruction of the spermatogenic stem cells populating the testes leads to permanent sterility. However, it is often possible to limit damage to these chemosensitive cells by using combination therapies in which the individual dosages of the most toxic agents are reduced. ${ }^{24-29}$

During treatment with chemotherapeutic agents, attempts should be made to minimize damage to spermproducing cells. One way to accomplish this is to use alternative chemotherapeutic agents such as methotrexate, which seems to be less harmful to testicular germ cells. Another way to decrease gonadotoxicity is to reduce the dose of alkylating agents and the number of cycles. ${ }^{27,28}$
It is not always possible to restore spermatogenesis following chemotherapy. ${ }^{24-26}$ It is therefore essential to offer patients the option of sperm cryopreservation prior to the initiation of chemotherapy. While some of these patients may have suboptimal semen quality prior to treatment, the use of in vitro fertilization technology coupled with intracytoplasmic sperm injection offers many men, even those with very low levels of sperm production, the potential to achieve a biologic pregnancy. ${ }^{24-26,29}$

Animal studies have shown that the use of certain hormonal treatments during the administration of cytotoxic chemotherapy may provide protective effects to germ cells. GnRH analogues and testosterone combine to suppress the concentration of intratesticular testosterone. When giving during cytotoxic chemotherapy, this type of treatment does not protect spermatogonia from damage. Rather, it appears to accelerate the return of sperm production after treatment is completed. Hormonal treatment may "desensitize" supporting cells of the testis, making them less susceptible to harm from cytotoxic therapy, thereby enabling recovery of spermatogenesis. The primary supporting cell, but Leydig cells also appear to be involved. Further studies are necessary to demonstrate whether these protective effects will also be achieved in humans. ${ }^{30-32}$

\section{Hormones}

Several hormonal agents influence male fertility, including anabolic steroids, testosterone replacement therapies, and antiandrogens.

\section{Anabolic steroids}

Anabolic steroids are being used not only by body builders, but also by athletes in all age groups. Unfortunately, these agents may have devas- 
tating effects on fertility. Anabolic steroids suppress the HPG axis via feedback inhibition. ${ }^{10}$ This causes severely reduced production of follicle-stimulating hormone (FSH) and $\mathrm{LH}$ resulting in hypogonadotropic hypogonadism. ${ }^{14}$ Steroid use may also cause erectile dysfunction by decreasing production of endogenous testosterone. High doses of anabolic steroids have also been shown to decrease sperm density and motility and increase morphologic abnormalities.

Fortunately, sperm production is likely to recover once steroid use is discontinued. While it generally takes 4 months for semen parameters to return to baseline levels, the continued presence of azoospermia has been reported 1 year after discontinuing anabolic steroid use. ${ }^{6,10}$ During this time, some men may benefit from injectable gonadotropins, such as human chorionic gonadotropin (hCG) replacement, to help stimulate sperm production and maintain endogenous testosterone production.

\section{Testosterone production}

With the increasing availability of safe, well-tolerated treatment methods, testosterone replacement therapy has become more common in clinical medicine. However, the use of exogenous androgens impairs spermatogenesis by inhibiting the HPG axis. ${ }^{6,10,14,19}$ Testosterone is also converted to estrogen in peripheral fat cells by the enzyme aromatase, increasing the negative feedback on the HPG axis. In men with decreased serum testosterone concentrations who wish to remain fertile, testosterone replacement in its various forms should not be used. An alternative in younger men with decreased serum testosterone concentrations is treatment with gonadotropins (such as hCG) or with the centrallyacting antiestrogen, clomiphene citrate. This agent has the advantage of being available in an oral form, while hCG requires repeated subcutaneous injection. However, both of these treatments will improve serum and intratesticular testosterone concentrations without decreasing gonadotropin levels through feedback inhibition.

\section{Other hormonal therapies}

Estrogens have been used in the past to treat advanced prostate cancer in men. Effects on sexual function include decreased libido, feminization, erectile dysfunction, and testicular atrophy. Finasteride is frequently used by men of reproductive age for its preventative effects on male-pattern baldness. ${ }^{33}$ While the use of this medication could conceivably alter intratesticular testosterone concentrations, there appears to be no evidence for any alteration in semen quality.

Saw palmetto is a commonly used herbal agent for symptoms of bladder outlet obstruction. While its mechanisms of action is largely unknown, it appears that it may exert some of its beneficial effect through slight estrogenic activity or by blocking the conversion of testosterone to DHT. ${ }^{34}$ While these effects could theoretically impair sperm production or function, no studies have yet been performed to evaluate this.

\section{Antibiotics}

Several commonly prescribed antibiotics may adversely affect fertility. Classically, high doses of nitrofurantoin have been shown to cause maturation arrest in the testis, most likely by preventing testicular cells from using carbohydrates and oxygen. ${ }^{35}$ However, low-dose, short-term therapy with nitrofurantoin has not been shown to have these same adverse effects. Erythromycin may reduce sperm motility and density ${ }^{35,36}$ Due to the fact that tetracyclines bind to mature spermatozoa, they have the potential to affect sperm motility. While gentamicin and neomycin may directly inhibit spermatogenesis, in vitro studies have failed to show an effect on mature spermatozoa.

\section{Semen Quality}

Several reports in the literature have suggested a possible decline in human semen quality during the last 50 to 60 years. ${ }^{37-40}$ However, the decline in sperm counts has been suspected just to reflect changes in the policy of infertility treatment, or a bias in selection of patients, rather than a biological phenomenon.

A systematic analysis of 61 studies was undertaken by Carlsen in 1992. It showed a significant decrease in sperm concentration (from 113 million $/ \mathrm{mL}$ to 66 million $/ \mathrm{mL}$ ) and semen volume (from $3.4 \mathrm{~mL}$ to $2.75 \mathrm{~mL}$ ) over the period 1938-1990..$^{40}$ These results have been discussed in the literature and have stimulated extensive research. In North America, the slope was somewhat less than previously reported. The decline in Europe was even greater than previously reported, whereas the few studies from other continents showed no trend. ${ }^{37,38}$ These results are consistent with those of Carlsen et al. and indicate that, after controlling for abstinence time, age, percent of men with proven fertility, and specimen collection method, there is a negative trend in sperm production in Europe and North America for the period 1934 to 1996. Over this period of time, the decrease is about $50 \%$.

The larger single study undertaken in this subject comes from the analysis of 1351 healthy men volunteering for sperm donation in the sperm bank of Paris. ${ }^{38}$ After taking into account all potential covariates, there remained a yearly decrease of $2.6 \%$ in sperm concentration, $0.3 \%$ in percentage of motile 
sperm, and $0.7 \%$ in the percentage of morphologically normal spermatozoa.

\section{Testicular dysgenesis syndrome}

Considerable concern has been raised in recent publications that estrogen-like compounds in either food or the environment cause adverse effects on reproductive health. ${ }^{1,3}$ There is clear evidence that reproductive disruption in wildlife may be caused by the environmental pollutants and more specifically by endocrine-disrupting compounds. ${ }^{40-42}$ Recently, cryptorchidism, hypospadias, testicular cancer, and poor semen quality have also been proposed to be the symptoms of one underlying cause, the testicular dysgenesis syndrome, which may develop during fetal life under the influence of environmental factors. ${ }^{3}$ However, there is only circumstantial evidence in humans that exposure to endocrine disrupters, especially diethylstilbestrol (DES), during pregnancy causes problems of reproductive health. The critical issue is whether there are enough high levels of endocrine disrupters in the ambient.

When these observations are brought together with the increasing incidence of testicular cancer in all the countries in which it is measured, and with the reported increased incidence of cryptorchidism and of hypospadias, the existence of a single syndrome, the "testicular dysgenesis syndrome" (TDS), that would associate these 3 elements, seems likely. These anomalies (decreasing sperm production, testicular cancer, and male genital tract malformations) are not necessarily associated in the same individuals, but they are statistically linked at the population level; however, one study showed that low sperm concentration, poor spermatozoa motility, and high proportion of morphologically abnormal spermatozoa were all associated with an increased risk in testicular cancer. ${ }^{1-4}$

\section{Hypospadias}

There is some evidence for an increased hypospadias rate during the last few decades. ${ }^{43,44}$ Several explanations have been proposed, including increased exposure to endocrine disruptors during fetal life. Another possible explanation is that, since published hypospadias rates are exclusively derived from birth-defect registries, artefacts in these registries may account for the reported changes over time. Recently, Dolk et al., discussed the possibility that the rise in hypospadias is caused by an increasing tendency to report minor hypospadias. ${ }^{45}$ However, the hypothesis is difficult to prove, since very few studies report the total distribution of cases by severity.

\section{Cryptorchidism}

There are also indications that cryptorchidism may have increased in incidence in several countries, but in general, cryptorchidism is registered more unreliably than hypospadias. ${ }^{46}$ Also, this anomaly is regarded as being associated with exposure to endocrine disruptors in utero.

Transinguinal descent of the testes also depends on androgens, but disrupted androgen action can only ex- plain a very small proportion of cases with cryptorchidism. ${ }^{47}$ Neonatal exposure to DES in male rats caused major developmental abnormalities of the testis, epididymis, vas deferens, seminal vesicles, and prostate when evaluated at the time of normal onset of puberty. $^{48}$

\section{Testicular cancer}

The most convincing evidence for a gene decline in male reproductive health in humans is the increase in testicular cancer noted in the recent past in several Western countries., ${ }^{4-27-29}$ Both cryptorchidism and hypospadias are associated with an increased risk of testicular cancer, based $n$ the observation that men with cryptorchidism/ hypospadias are over-represented among patients with testicular cancer. ${ }^{1}$

The hypothesis that endocrine disruption can cause cancer in humans is based on the association between DES exposure of pregnant women and clear cell adenocarcinoma of the vagina and cervix in their female offspring. Some of the male offspring of women who took DES show pseudohermaphroditism and genital malformations, including epididymal cysts, small testes, microphallus, and reduced semen quality. ${ }^{49}$ Follow-up surveys of DES-exposed male offspring have shown no impairment in fertility or sexual function, or evidence of an increased risk of testicular cancer. Dysgenic testes have a very high risk of developing testicular cancer in adulthood; these cancers seem to arise from premalignant gonocytes or in situ carcinoma cells. $^{1,29}$

\section{RESUMO}

PASQUALOTTO FF e col. Efeitos da terapia medicamentosa, àlcool, cigarros e substância deletérias para o sistema endócrino na infertilidade masculina. Rev. Hosp. Clín.
Fac. Med. S. Paulo 59(6):375-382, 2004.

A infertilidade afeta até $15 \%$ da população sexualmente ativa e em
$50 \%$ dos casos, o fator masculino está envolvido, como problema primário ou em combinação com causas de origem feminina. Como muitas drogas comumente encontradas e medicações 
podem ter efeitos deletérios na infertilidade masculina, a avaliação médica deve incluir uma discussão sobre o uso de drogas recreacionais e ilícitas, medicamentos e outras substâncias podem prejudicar a fertilidade. Com o conhecimento de quais drogas e medicamentos podem ser prejudiciais à fertilidade talvez seja possível mudar os hábitos ou a posologia das medicações para diminuir os efeitos adversos na fertilidade e aumentar as chances de engravidar com sucesso.

Preocupações referentes ao desenvolvimento sexual masculino e reprodução tem mudado para a pior nos últimos 30-50 anos. Embora alguns relatos não demonstrem modificações, outros sugerem que a concentração espermática esteja diminuindo e que a incidência de anormalidades do desenvolvimento como hipospádia e criptorquidia parecem estar aumentando, assim como a incidência de câncer de testículo. Estas preocupações sobre a possibilidade do ambiente estar contaminado com substâncias químicas naturais ou sintéticas - que podem interagir com o sistema endócrino.

UNITERMOS: Semen. Endócrino. Espermatozóides. Álcool. Cigarros. Drogas.

\section{REFERENCES}

1. Weber RFA, Pierik FH, Dohle GR, Burdorf A. Environmental influences on male reproduction. BJU International 2002;89:143-8.

2. Kogevinas M. Human health effects of dioxins: cancer, reproductive and endocrine systems effects. Human Reprod Update 2001;7:331-9.

3. Skakkebaek NE, Rajpert-De Meyts E, Main KM. Testicular dysgenesis syndrome: an increasingly common developmental disorder with environmental aspects. Hum Reprod 2001;16:972-8.

4. Pasqualotto FF, Agarwal A, Pasqualotto EB, Thomas Jr. AJ. Detection of testicular cancer in men presenting with infertility. Rev Hosp Clin Fac Med S Paulo 2003;58(2):75-80.

5. Cozzolino DJ, Lamb DJ. Are endocrine disruptors a cause of male reproductive defects? Contemporary Urology 2000,19:6974.

6. Monoski M, Nudell DM, Lipshultz LI. Effects of medical therapy, alcohol, and smoking on male fertility. Contemporary Urology 2002; June:57-63.

7. Raleigh VS. Trends in world population: how will the millennium compare with the past? Hum Reprod. Update 1999;5:500-5.

8. Van Look PFA. Population growth in the new Millennium: implications for patterns and trends in global health. In Healy DL; Kovacs, GT; Mclachlan, R; Rodriguez-Armas, O. $1^{\text {st }}$ ed. Reproductive Medicine in the Twenty-first Century. Parthenon Publishing Group 2001, 3-20.

9. World Health Organization WHO Laboratory manual for the examination of human semen and sperm-cervical mucus interaction, Cambridge, Cambridge University Press, 1999.

10. Thompson ST. Prevention of male infertility: an update. Phenothiazines 1994;21(3):365-76.

11. Sharpe RM, Skakkebaek NE. Are oestrogens involved in falling sperm counts and disorder of the male reproductive tract? Lancet 1993;341:1392-5.

12. Cooper RL, Kavlock RJ. Endocrine disruptors and reproductive development: a weight-of-evidence overview. J Endocrinol 1997;152(2):159-66.
13. Ginsburg J. Tackling environmental endocrine disruptors. Lancet 1996;347(9014):1501-2.

14. Buffum J. Pharmacosexology: the effects of drugs on sexual function a review. J Psychoactive Drugs 1983;14:5-44.

15. Purohit V. Can alcohol promote aromatization of androgens to estrogens? A review. Alcohol 2000;22(3):123-7.

16. Stillman RJ, Rosemberg MJ, Sachs BP. Smoking and reproduction. Fertil Steril 1986;46(4):545-66.

17. Lucon AM, Pasqualotto FF, Peng BC, Hallak J, Arap S. Do tobacco and caffeine impair semen characteristics in men with fertility proved? [Abstract 1394]. J Urol 2002;167(4):351.

18. Klaiber EL, Broverman DM. Dynamics of estradiol and testosterone and seminal fluid indexes in smokers and nonsmokers. Fertil Steril 1988;50(4):630-4.

19. Buffum J. Pharmacosexology update: prescription drugs and sexual function. J Psychoactive Drugs 1986: 18(2): 97-106.

20. Hershlag A, Cooper GW, Benoff S. Pregnancy following discontinuation of a calcium channel blocker in the male partner. Hum Reprod 1995; 10(3): 599-606.

21. Benoff S, Jacob A, Hurley I. Male infertility and environmental exposure to lead and cadmium. Hum Reprod Update 2000;6:107-21.

22. Katsoff D, Check JH. A challenge to the concept that the use of calcium channel blockers causes reversible male infertility. Hum Reprod 1997;12(7):1480-2.

23. Debruyne FM. Alpha blockers: are all created equal? Urology 2000;56:20-2

24. Hallak J, Kolettis PN, Sekhon V, Thomas AJ Jr, Agarwal A. Sperm cryopreservation in patients with leukemia: is it worth the effort? Cancer 1999;85:1973-8

25. Hallak J, Kolettis PN, Sekhon VS, Thomas Aj Jr, Agarwal A. Sperm cryopreservation in patients with testis cancer. Urology 1999:54:894-9. 
Effects of medical therapy, alcohol, smoking, and endocrine disruptors Pasqualotto FF et al.

26. Hallak J, Hendin BN, Thomas AJ, Agarwal A. Investigation of fertilizing capacity of cryopreserved spermatozoa from patients with cancer. J Urol 1998;159:1217-20.

27. Costabile RA. The effects of cancer and cancer therapy on male reproductive function. J Urol 1993;149:1327-32.

28. Costabile RA, Spevak M. Cancer and male factor infertility. Oncology 1998;12:557-68.

29. Turek PJ, Lowther DN, Carrol PR. Fertility issues and their management in men with testis cancer. Urol Clin North Am $1998 ; 25: 5217-31$.

30. Howell S, Shalet S. Gonadal damage from chemotherapy and radiotherapy. Endocrinol Metab Clin North Am 1998;27(4):927-43.

31. Howell S, Shalet S. Testicular function following chemotherapy. Hum Reprod Update 2001;7(4):363-9.

32. Shuttlesworth GA, de Rooij DG, Huhtaniemi I, Reissmann T, Russell LD, Shetty G, et al. Enhancement of A spermatogonial proliferation and differentiation in irradiated rats by gonadotropin-releasing hormone antagonist administration. Endocrinology 2000;141(1):37-49.

33. Overstreet JW, Fuh VL, Gould J, Howards SS, Lieber MM, Hellstrom W, et al. Chronic treatment with finasteride daily does not affect spermatogenesis or semen production in young men. J Urol 1999;162(4):1295-1300.

34. Marks LS, Partin AW, Epstein JI, Tyler VE, Simon I, Macairan ML, et al. Effects of a saw palmetto herbal blend in men with symptomatic benign prostatic hyperplasia. J Urol 2000;163(5):1451-6.

35. Schlegel PN, Chang TS, Marshall FF. Antibiotics: potential hazards to male fertility. Fertil Steril 1991;55(2):235-42.

36. King K, Chan PJ, Patton WC, King A. Antibiotics: effects on cryopreserved-thawed human sperm motility in vitro. Fertil Steril 1997;67(6):1146-51.

37. Jorgensen N, Andersen AG, Eustache F, Irvine DS, Suominen J, Petersen $\mathrm{JH}$, et al. Regional differences in semen quality in Europe. Hum Reprod 2001;16:1012-9.
REV. HOSP. CLÍN. FAC. MED. S. PAULO 59(6):375-382, 2004

38. Auger J, Kutmann JM, Czyglik F, Jouanett P. Decline in semen quality of fertile men during the last 20 years. New Engl J Med 1995;332:281-5.

39. Bostoffe E, Serup J, Rebbe H. Has the fertility of Danish men declined through the years in terms of semen quality? A comparison of semen qualities between 1952 and 1972. Int J Fertil 1993;28:91-5.

40. Carlsen E, Giwerman AJ, Keiding N, Skakkebaek NE. Evidence for decreasing quality of semen during past 50 years. BMJ 1992;305:609-13.

41. Olsen J. Is human fecundity declining-and does occupational exposures play a role in such a decline if it exists? Scand J Work Environ Health 1994;20:72-7.

42. Wilcox AJ. Fertility in men exposed prenatally to diethylstilbestrol New Engl J Med 1995;332:1411-6.

43. Paulozzi LJ, Erickson JD, Jackson RJ. Hypospadias trends in two US surveillance systems. Pediatrics 1997;100:831-4.

44. Aho M, Koivisto A-M, Tammela TLJ, Auvinen A. Is the incidence of hypospadias increasing? Analysis of Finnish hospital discharge data 1970-1994. Environ Health Perspect 2000:108:463-5.

45. Dolk H. Rise in prevalence of hypospadias. Lancet 1998;351:770.

46. Hutson JM, Hasthorpe S, Heyns CF. Anatomical and functional aspects of testicular descent and cryptorchidism. Endocr Rev $1997 ; 18: 259-80$

47. Nef S, Parada LF. Cryptorchidism in mice mutant for Ins 13. Nature Genet 1999;22:295-9.

48. Walker AH, Bernstein L, Warren DW, Warner NE, Zheng X, Henderson BE. The effect of in utero ethinyl oestradiol exposure on the risk of cryptorchid testis and testicular teratoma in mice. Br J Cancer 1990;62:599-602.

49. Leary FJ, Resseguie LJ, Kurland LT, O'Brien PC, Emslander RF, Noller KL, et al. Males exposed in utero to diethylstilbestrol JAMA 1984;252:2984-9. 